\title{
EFEKTIVITAS MODEL STUDENT FACILITATOR AND EXPLAINING TERHADAP KEMAMPUAN KOMUNIKASI MATEMATIS SISWA SMP DITINNJAU DARI SELF-EFFICACY
}

\author{
Asep Ikin Sugandi ${ }^{1}$, Padillah Akbar ${ }^{2}$ \\ ${ }^{1,2}$ Program Studi Pendidikan Matematika Fakultas Pendidikan Matematika dan Sains IKIP Siliwangi \\ asepikinsugandi@ikipsiliwangi.ac.id
}

\begin{abstract}
This research is based on the low mathematical communication skills of junior high school students in the city of Cimahi and the purpose of this study is to examine the Student Facilitator and Explaining model of junior high school students' mathematical communication skills in terms of self-efficacy. The type of research used is quantitative with a quasi-experimental method, The population in this study were all eighth grade students in Cimahi city while the sample was chosen for two VII classes from one junior high school in Cimahi city. The instrument used in this study was a set of 5 students' mathematical communication skills questions and nontests containing 25 questions about self-efficacy. These questions have met the requirements of a good instrument in terms of validity, reliability, differentiation and difficulty index. Based on the results of data processing, the following results were obtained: The application of the Student Facilitator Explaining Model was effective in achieving students' mathematical communication skills in terms of overall and self-efficacy aspects.
\end{abstract}

Keywords: effectiveness, models, student facilitators and explaining, junior high school students, self-efficacy

\begin{abstract}
Abstrak
Penelitian ini didasari masih rendahnya kemampuan komunikasi matematis siswa SMP di kota cimahi dan tujuan dari penelitian ini adalah menelaah efektivitas model Student Facilitator and Explaining terhadap kemampuan komuunikasi matematis siswa SMP ditinjau dari self efficacay. Jenis penelitian yang digunakan adalah kuantitatif dengan metode kuasi eksperimen, Populai dalam penelitian adalah seluruh siswa kelas VII SMP di kota Cimahi sedangkan sampelnya dipilih dua kelas VII dari salah satu SMP di kota Cimahi. Instrumen yang digunakan dalam penelitian ini adalah seperangkat soal kemampuan komunikasi matematik siswa yang berjumlah 35 siswa dan non tes yang berisi 25 pertanyaan mengenai self-efficacy. Soal soal tersebut sudah memenuhi syarat instrumen yang baik ditinjau dari segi validitas, reliabilias, daya pembeda dan indeks kesukaran. Berdasarkan hasil pengolahan data didapat hasil sebagai berikut : Penerapan Model Student facilitator explaining efektif dalam pencapaian kemampuan komunikasi matematis siswa ditinjau secara keseluruhan maupun dari segi self-efficacy, terdapat interaksi antara model pembelajaran student facilitator and explaining dan self-efficacy terjadap kemampuan komunikasi siswa SMP.
\end{abstract}

Kata Kunci: Efektivitas, Model, Student Facilitator And Explaining, Siswa SMP, Self Efficacy

\section{PENDAHULUAN}

Pembelajaran matematika merupakan pembelajaran penting yang harus dikuasai setiap individu sejak dini karena merupakan dasar ilmu yang dipakai dalam kehidupan sehari-hari manusia (Sugandi \& Akbar, 2019; Akbar et al., 2018) kemampuan komunikasi dalam pembelajaran matematika atau disebut juga kemampuan komunikasi matematis sangat penting dalam menunjang keberhasilan belajar siswa.

Asnawati (2017) yang menyatakan bahwa komunikasi adalah suatu pertukatan informasi dianatara dua individu atau lebih melalui sistem yang lazim digunakan dengan menggunakan simbol-simbol dan tindakan atau perilaku. Kemampuan komunikasi matematik adalah suatu kemampuan dimana siswa menyampaikan sesuatu yang diketahuinya melalui peristiwa dialog atau saling berhubungan yang terjadi di lingkungan kelas (Aminah et al., 2018). 
Kemampuan komunikasi diperlukan dalam membangun pengetahuan matematika siswa dalam menyelesaikan persoalan matematika secara benar dan tepat.. Sesuai dengan pendapat Gurreiro (Izzati \& Suryadi, 2010), komunikasi matematis merupakan alat bantu dalam melakukan transfer pengetahuan matematika atau sebagai fundamen dalam membangun dan mengembangkan pengetahuan matematika. Siswa yang memiliki kemampuan komunikasi yang baik akan dapat menyatakan ide atau gagasan matematisnya dengan singkat, tepat dan logis serta dapat menumbuhkembangkan pemahaman matematika, dan mempertajam cara berpikir matematisnya. Lebih lanjut (Syasri et al., 2018) mengemukakan bahwa kemampuan komunikasi matematis adalah kemampuan siswa dalam mengkomunikasiikan berbagai ide matematis secara lisan ataupun tulisan sehingga siswa dapat mengembangkan secara mandiri pemahaman yang telah dimilikinya dan dapat membangun pengetahuannya dan mengaitkan pengalaman belajarrnya dalam memahami konsepkonsep matematika yang sebenarnya. Berdasarkan uraian tersebut maka dapat disimpulkan bahwa kemampuan komunikasi matematis merupakan kemampuan menyatakan ide dengan simbol-simbol, grafik, atau diagram untuk menjelaskan suatu keadaan atau masalah

Namun kenyataan dilapangan menunjukkan bahwa kemampuan komunikasi matematis masih rendah. Hal ini dilihat dari hasil TMSS 2011 (Mullis et al., 2012), bahwa Indonesia masih berada di urutan 38 dari 42 negara, kemudian diperkuat dari PISA di bawah OECD pada tahun 2015, Indonesia berada pada rangking 62 dari 70 negara dengan skor kemampuan matematika sebesar 386 dan ratarata skor kemamapuan matematika dunia sebesar 494 (OECD, 2016). Menurut penelitian (Wijayanto et al., 2018) kemampuan komunikasi matematis siswa SMP di kota Cimahi pada materi segitiga dan segiempat tergolong rendah, Sementara menurut penelitian (Niasih et al., 2019) kemampuan komunikasi matematis siswa SMP di kota Cimahi pada materi statistika juga tergolong rendah, Sedangkan dalam penelitian (Aminah et al., 2018) mengemukakan bahwa pada materi himpunan, kemampuan komunikasi matematis siswa SMP di kota Cimahi juga tergolong rendah. Dari beberapa penelitian tersebut dapat disimpulkan bahwa kemampuan komunikasi matematis siswa SMP di kota Cimahi tergolong rendah.

Salah satu usaha dalam mengembangkan kemampuan komunikasi yang masih rendah, diperlukan pemilihan model belajar yang dapat meningkatkan aktivitas siswa dalam belajar. Salah satu model yang diperkirakan dapat meningkatkan kemampuan komunikasi adalah model belajar student facilitator and explaining. Model student facilitator and explaining menurut (Huda, 2013) adalah model yang menyajikan materi pembelajaran dengan diawali penjelasan terbuka, memberikan peluang agar siswa dapat menjelaskan kembali kepada siswa lainnya dan sebagai langkah terakhir adalah penyampaian materi secara keseluruhan kepada siswa. Dengan demikian dapat disimpulkan bahwa student facilitator and explaining merupakan model pembelajaran koperatif yang memberikan kesempatan agar siswa dapat mengkomunikasikan segala kemampuan yang telah dimiliki siswa kepada seluruh anggota dalam kelompoknya.

Pembelajaran Student Facilitator and Explaining menuntut siswa karena pembelajaran ini 
dapat mewujudkan tujuan Pendidikan. Model pembelajaran ini menuntut siswa untuk dapat mengemukakan gagasan dan pendapatnya sehingga diperkirakan dapat meningkatkan kemampuan komunikasi siswa,

Disamping perlunya dikembangkan suatu model belajar, untuk meningkatkan kemampuan komunikasi matematis diperlukan suatu aspek afektif yang diperkirakan dapat meningkatkan kemampuan komunikasi. Seseorang akan berhasil dalam kegiatan pembelajaran yang optimal jika ia memiliki minat dalam suatu mata pelajaran. Keyakinan terhadap kemampuan yang telah dimiliki siswa merupakan sikap positif yang mengakibatkan hasil belajar meningkat dan menyebabkan siswa sukses dalam belajarnya (Hidayat \& Sariningsih, 2018). Hal ini sejalan pendapat Canfields \& Watkins (Hendriana et al., 2017) menyatakan pandangan siswa terhadap kemampuannya dapat mempengaruhi kesukseksan siswa tersebut, pandangan itu selalu mengalami pengulangan dan berjalan secara kontinu, sulit untuk diubah, dan menjadi kebiasaan pada diri siswa. Siswa yang kurang dapat menyampaikan gagasan matematis dikarenakan siswa tidak memiliki keyakinan pada diri sendiri yang berhubungan dengan kemampuan yang siswa telah miliki, kemampuan afektif ini disebut selfefficacy (Sariningsih \& Purwasih, 2017), self-efficacy merupakan keyakinan seorang siswa dengan kemampuannya dalam pembelajaran matematika dan siswa penting untuk memiliki kemampuan selfefficacy.

Berdasarkan permasalahan diatas, maka peneliti tertarik untuk menganalisis pengaruh model belajar student fasilittor and explaining terhadap kemampuan komunikasi siswa SMP ditinjau dari keseluruhan dan self-efficacy, rumusan masalah dalam penelitian ini adalah Apakah penerapan model student facilitator and explaining efektif terhadap kemampuan komunikasi matematis siswa ditinjau dari keseluruhan dan self- efficacy dan apakah terdapat interaksi antara student facilitator and explaining dan self-efficacy terhadap kemampuan komunikasi matematis siswa.

\section{METODE}

Metode yang digunakan pada penelitian ini adalah metode kuasi eksperimen, karena adanya manipulasi perlakuan berupa pemberian model belajar student facilitator and explaining. Adapun desainnya berbentuk pre-pos tes kelompok kontrol desain:

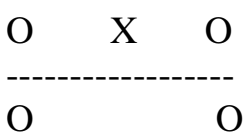

Keterangan :

$\mathrm{O}=$ Tes awal atau tes akhir

$\mathrm{X} \quad=$ Perlakuan berupa penerapan model student facilitator and explaining

----- = Pengambilan sampel secara acak kelas 
Populasi pada penelitian ini adalah seluruh siswa kelas VIII SMP di kota Cimahi, sedangkan sampelnya dipilih dua kelas VII dari salah satu SMP di kota Cimahi. . Instrumen yang digunakan dalam penelitian ini adalah seperangkat soal kemampuan komunikasi matematik siswa yang berjumlah 5 soal dan non tes berbentuk skala Likert yang berisi 25 pertanyaan mengenai self-efficacy. Soal soal tersebut sudah memenuhi syarat instrumen yang baik ditinjau dari segi validitas, reliabilias, daya pembeda dan indeks kesukaran.

\section{HASIL}

Berdasarkan hasil pengolahan data terhadap tes awal kemampuan komunikasi matematis didapat hasil seperti Tabel 1

\section{Tabel 1.}

Deskripsi Tes Akhir Kemampuan Komunikasi Siswa

\begin{tabular}{cccccccccc}
\hline Self & \multicolumn{4}{c}{ Model Pembelajaran } & \multicolumn{3}{c}{ Total } \\
\cline { 2 - 7 } Efficacy & \multicolumn{4}{c}{ Student Facilitator and Explaining } & \multicolumn{1}{c}{ Biasa } & & & \\
\cline { 2 - 9 } & $\bar{x}$ & $\mathrm{~s}$ & $\mathrm{n}$ & $\bar{x}$ & $\mathrm{~s}$ & $\mathrm{n}$ & $\bar{x}$ & $\mathrm{~s}$ & $\mathrm{n}$ \\
\hline Tinggi & 82,44 & 2,85 & 16 & 78,00 & 0,00 & 2 & 81,94 & 3,04 & 18 \\
Sedang & 70,60 & 4,76 & 15 & 69,60 & 3,85 & 15 & 70,10 & 4,29 & 30 \\
Rendah & 67,50 & 5,57 & 4 & 59,17 & 5,00 & 18 & 60,68 & 5,96 & 22 \\
Total & 75,66 & 7,51 & 35 & 64,71 & 7,47 & 35 & 70,19 & 9,26 & 70 \\
\hline
\end{tabular}

Skor Maksimum 100

1) Secara keseluruhan rata-rata kemampuan komunikasi matematis siswa pada tes akhir sebesar 70,19 (skor maksimum 100) . Hal ini menunjukkan bahwa kemampuan komunikasi matematis siswa secara keseluruhan termasuk kategori sedang, $(70,19 \%)$.

2) Skor kemampuan komunikasi matematis siswa secara keseluruhan berdasarkan jenis model pembelajaran (Student Facilitator and Explaining dan biasa adalah 75,66 dan 64,71; simpangan baku masing-masing 7,51 dan 7,47; dan jumlah siswa 35 dan 35. Hal ini menunjukkan bahwa kemampuan komunikasi matematis siswa yang pembelajarannya menggunkan model Student Facilitator and Explaining lebih baik daripada pembelajaran biasa.

3) Skor kemampuan komunikasi matematis siswa berdasarkan self efficacy (tinggi, sedang dan rendah) adalah : 81,94, 70,10 dan 60,68; simpangan baku 3,04, 4,29 dan 9,26; jumlah siswa 18,30 dan 22. Hal ini menunjukkan bahwa bahwa kemapuan komunikasi matematis siswa yang memilik self-efficacy kategori tinggi lebih baik daripada yang memiliki kategori sedang maupun rendah, dan kemampuan komunikasi matematis siswa yang memiliki self-efficacy sedang lebih baik daripada yang berkategori rendah.

Namun hal ini masih bersifat analisis deskriftif untuk menguji kebenarannya harus menggunakan uji statistik inferensial. Untuk selanjutnya menguji normalitas data, uji yang digunakan untuk menguji normalitas data ini digunakan uji Kolmogorov Smirnov, dengan kriteria uji terima Ho, jika nilai sign. 
$>0,05$.

Berdasarkan hasil pegolahan data maka didapat hasil uji normalitas berdasarkan model belajar seperti pada Tabel 2

Tabel 2.

Hasil Uji Normalitas Berdasarkan Model Pembelajaran

\begin{tabular}{cccc}
\hline Model & Statistik & df & Sign. \\
\hline Eksperimen & 0,147 & 35 & 0,053 \\
Kontrol & 0,103 & 35 & 0,200 \\
\hline
\end{tabular}

Berdasarkan Tabel 2 didapat nilai sign. untuk kelas student facilitator and explaining sebesar 0,053 dan untuk kelas biasa didapat nilai sign 0,200, karena nilai sign. kedua kelas lebih besar dari 0,05 maka disimpulakan bahwa data tes akhir kedua kelas berdistribusi normal. Untuk selanjutnya diuji normalitas berdasarkan self- efficacy (tinggi, sedang dan rendah ) dengan menggunakan uji Kolmogorov-Smirnov dengan kriteri uji terima Ho, jika sing. > 0,05.

Berdasarkan hasil pengolahan data maka didapat hasil uji normalitas berdasarkan kategori selfefficacy siswa sebagai berikut :

Tabel 3.

Hasil Uji Normalitas Berdasarkan Kategori Self-Efficacy

\begin{tabular}{cccc}
\hline Self-Efficacy & Statistik & df & Sign. \\
\hline Tinggi & 0,159 & 18 & 0,200 \\
Sedang & 0,117 & 30 & 0,200 \\
Rendah & 0,148 & 22 & 0,200 \\
\hline
\end{tabular}

Dari Tabel 3 didapat nilai sig, untuk kelas self -efficacy kategori tinggi, sedang dan rendah masing-masing sebesar 0,200; karena nilai sign ketiga kelas lebih besar 0,05 maka data ketiga kelas tersebut berdistibusi normal. Untuk selanjutnya dilakukan uji homogenitas dengan menggunkan uji lavene, dengan kriteria terima Ho, jika nilai sign. > 0,05.

Berdasarkan hasil pengolahan data maka didapat hasil uji homogenitas terhadap kemampuan komunikasi matematis siswa sebagai berikut :

\section{Tabel 4.}

Hasil Uji Homogenitas kemampuan Komunikasi Matematis Siswa

\begin{tabular}{cccc}
\hline F & df1 & df2 & Sign. \\
\hline 0,3855 & 5 & 64 & 0,647 \\
\hline
\end{tabular}

Berdasarkan Tabel 4. didapat nilai sig. 0,647, karena nilai sign. lebih besar dari 0,05 maka disimpulkan bahawa varians kemamapuan komunikasi matematis siswa homogen. Untuk selanjutnya untuk menguji hipotesis digunakan uji Anova dua jalur.

Berdasarkan hasil uji Anova dua jalur terhadap kemampuan komunikasi matematis dengan factor 
model pembelajaran dan kategori Self-efficacy didapat hasil sebagai berikut :

Tabel 5.

Rangkuman Uji Anova Dua Jalur Kemampuan Komunikasi Siswa dengan faktor Model pembelajaran dan Kategori Self-Efficacy

\begin{tabular}{|c|c|c|c|c|c|c|}
\hline Sumber & $\begin{array}{c}\text { Jumlah } \\
\text { Kuadrat }\end{array}$ & dk & $\begin{array}{c}\text { Rata-rata } \\
\text { Kuadrat }\end{array}$ & F & Sign. & Kesimpulan \\
\hline Model & 189,373 & 1 & 189,373 & 10,407 & 0,002 & Ho titolak \\
\hline Self-Efficacy & 1321,998 & 2 & 660,999 & 36,324 & 0,000 & Ho ditolak \\
\hline Interaksi & 124,765 & 2 & 62,382 & 3,428 & 0,039 & Ho diterima \\
\hline
\end{tabular}

Dari perhitungan pada Tabel 5 didapat analisis kemampuan komunikasi matematis siswa berdasarkan beberapa hal, diantranya :

\section{Berdasarkan model pembelajaran}

Adapun hipotess yang akan diuji sebagai berikut :

Ho : Tidak terdapat perbedaan kemampuan komunikasi siswa antara yang pembelajarannya menggunakan model student facilitator and explaining dengan pembelajaran biasa.

$\mathrm{H}_{1} \quad$ : Kemampuan Komunikasi matematis siswa yang pembelajarannya menggunakan model student facilitator and explaining lebih baik daripada pembelajaran biasa.

Kriteria pengujian terima Ho jika nilai sgn. > 0,05

Dari Tabel 5 didapat nilai sign. sebesar 0,002, karena nilai sign. $<0,05$, maka Ho ditolak, sehingga disimpulkan bahwa kemampuan komunikasi matematis siswa yang pembelajarannya menggunakan model student facilitator and explaining lebih baik daripada pembelajaran biasa.

Interaksi antara model student facilitator and explaining dengan self efficacy terhadap kemampuan komunikasi matematis siswa

Adapun hipotesis yang akan diuji diformulasikan sebagai berikut :

Ho : Tidak terdapat interaksi antara model student facilitator and explaining dengan self efficacy terhadap kemampuan komunikasi matematis siswa.

$\mathrm{H}_{1}$ :Terdapat interaksi antara model student facilitator and explaining dengan self efficacy terhadap kemampuan komunikasi matematis siswa.

Dari Tabel 5 didapat nilai sign sebesar 0,039, karena nilai sign. $<0,05$ maka dapat disimpulkan bahwa Terdapat interaksi antara model student facilitator and explaining dengan self-efficacy terhadap kemampuan komunikasi matematis siswa. Hal ini menyatakan bahwa model student facilitator and explaining dengan self-efficacy secara bersama-sama memberikan kontribusi yang positif terhadap kemampuan komunikasi mateatis.

\section{Berdasarkan Self-Efficacy}

Adapun Hipotesis yang akan diuji diformulasikan sebagai berikut :

Ho

$\mathrm{H}_{1} \quad$ : paling tidak ada satu kelompok yang berbeda dengan lainnya

Kriteria pengujian : terima Ho jika nilai sign. > 0,05 
Dari Tabel 5 didapat nilai sign. $<0,05$, maka Ho ditolak. Hal ini berarti paling tidak ada satu kelompok yang berbeda dengan lainnya. Untuk mengetahui tingkat Self-Efficacy yang mana yang berbeda secara signifikasn dalam hal kemampuan komunikasi maka digunkan uji Scheffe, hasil perhitungan disajikan pada Tabel 6 berikut ini ;

\section{Tabel 6.}

Uji Scheffe Rata-rata Kemampuan Komunikasi Matematis berdasarkan kategori Self-Efficacy

\begin{tabular}{ccccc}
\hline Self-Efficacy 1 & Self-Efficacy 2 & $\begin{array}{c}\text { Perbedaan Rata- } \\
\text { rata }\end{array}$ & Sign. & Ho \\
\hline Tinggi & Sedang & 10,12 & 0,000 & Ditolak \\
& Rendah & 16,88 & 0,000 & Ditolak \\
Sedang & Rendah & 6,77 & 0,000 & \\
\hline
\end{tabular}

Dari Tabel 6 didapat bahwa nilai sign $<0,05$ untuk setiap pasangan kategori self-efficacy maka Ho ditolak. Dengan demikian dapat ditarik kesimpulan bahwa kemampuan komunikasi matematis siswa pada self-efficacy tinggi lebih baik daripada siswa yang memiliki self-efficacy sedang dan rendah. Demikian juga, kemampuan komunikasi matematis siswa pada self-eficacy sedang lebih baik dari pada self-efficacy rendah.

Berdasarkan hasil pengolahan data didapat bahwa penerapan Student Facilitator and Explaining efektif terhadap pencapaian kemampuan komunikasi matematika siswa ditinjau dari keseluruhan. Hal ini sejalan dengan penelitian (Sugandi \& Bernard, 2018), (Asnawati, 2017), (Damayanti et al., 2018) yang menyatakan bahwa penerapan model atau pendekatan inovatif efektif dalam meningkatkan kemampuan komunikasi matematis siswa, (Sugandi \& Bernard, 2018) meneliti menggunakan pendekatan kontektual pada siswa SMP, Asnawati meneliti menggunakan Model Kooperatif tipe Teams-Games Tournaments pada siswa SMP sedangkan Damayanti, Dahlan \& Herrhyanto menngunakan model Accelerated Learning pada siswa SMP.

Adapun penyebab kemampuan Komunikasi matematis siswa yang pembelajarannya menggunakan model Studet facilitatot and explaining lebih baik dari pendekatan biasa adalah sebagai berikut: Model pembelajaran kooperatif Student facilitator and explaining berpusat pada siswa, sebagaimana yang dikemukakan (Huda, 2013) bahwa model belajar student facilitator and explaining adalah kegiatan belajar dengan mempresentasikan serangkaian materi pembelajaran yang dimulai dengan penjelasan awal oleh guru secara terbuka, dilanjutkan memberi peluang pada siswa agar dapat menjelaskan kembali pada teman dalam kelompoknya, dalam kegiatan akhir semua materi disajikan untuk siswa sehingga menumbuhkan motivasi belajar bagi semua siswa. Hal ini sesuai penelitian (Witarsa, 2017) yang menyebutkan bahwa penerapan model Student facilitator and explaining mempengaruhi kesediaan siswa untuk berbicara mengeluarkan pendapatnya masing-masing pada saat belajar serta mempengaruhi sikap dan keberanian untuk mengeluarkan ide dari hasil analisa yang dilakukan dalam pembelajaran. Dari dua pendapat di atas dapat disimpulkan bahwa model Student facilitator and explaining efektif dalam meningkatkan kemampuan komunikasi matematis siswa, 
karena kesedian siswa untuk mengeluarkan ide atau gagasan secara lisan maupun tulisan dengan benda, gambar merupakan indikator kemampuan komunikasi matematis.

Berdasarkan pengolahan data terhadap self-efficacy didapat kesimpulan bahwa kemampuan komunikasi siswa yang memiliki self-efficacy dengan kategori tinggi lebih baik daripada yang berkategori sedang maupun rendah. Hal ini sejalan dengan penelitian Hendriana \& Kadarisma (2018) yang menyatakan bahwa bahwa self-efficacy mempunyai pengaruh yang signifikan pada kemampuan komunikasi matematik, hal ini sejalan dengan penelitian (Fonna \& Mursalin, 2018), bahwa selfefficacy memiliki asosiasi yang positif dengan representasi yang merupakan bagian dari komunikasi matematis. Begitu juga sejalan penelitian (Kurnia et al., 2018) yang menyatakan bahwa siswa yang memiliki kemandirian dan self-efficacy yang baik maka pencapaian kemampuan komunikasi matematis pun akan baik pula.

\section{KESIMPULAN}

Berdasarkan hasil pengolahan data didapat kesimpulan sebagai berikut : 1) Penerapan model student facilitator and explaining efektif terhadap pencapaian kemampuan komunikasi matematis siswa ditinjau secara keseluruhan maupun dari segi self-efficacy. 2) Terdapat interaksi antara model student facilitator and explaining dan self-efficacy terhadap kemampuan komunikasi matematis siswa

Adapun dalam saran dalam penelitian ini adalah : 1) Model student facilitator and explaining dapat digunakan dalam pembelajaran matematik terutama dalam topik-topik terpilih dan esensial. 2) Untuk penelitian selanjutnya penggunaan model student facilitator and explaining dan dibantu dengan penggunaan ICT dalam upaya meningkatkan aktivitas belajar siswa.

\section{DAFTAR PUSTAKA}

Aminah, S., Wijaya, T. T., \& Yuspriyati, D. (2018). Analisis Kemampuan Komunikasi Matematis Siswa Kelas Viii Pada Materi Himpunan. Jurnal Cendekia: Jurnal Pendidikan Matematika, 2(1), $15-22$.

Akbar, P., Hamid, A., Bernard, M., Sugandi, A. I., Disposition, M., \& Matematik, D. (2018). Analisis kemampuan pemecahan masalah dan disposisi matematik siswa kelas xi sma putra juang dalam materi peluang. 2(1), 144-153.

Aminah, S., Wijaya, T. T., \& Yuspriyati, D. (2018). Analisis Kemampuan Komunikasi Matematis Siswa Kelas Viii Pada Materi Himpunan. Jurnal Cendekia: Jurnal Pendidikan Matematika, 2(1), 15-22. https://doi.org/10.31004/cendekia.v2i1.29

Asnawati, S. (2017). Peningkatan kemampuan komunikasi matematis siswa smp dengan pembelajaran kooperatif tipe teams-gamestournaments. Euclid, 3(2).

Damayanti, D., Dahlan, J. A., \& Herrhyanto, N. (2018). Penerapan Metode Accelerated Learning dalam Pembelajaran Matematika untuk Meningkatkan Kemampuan Komunikasi Matematis Siswa SMP. Integral: Pendidikan Matematika, 9(2), 15-24. 
Fonna, M., \& Mursalin, M. (2018). Role of Self-Efficacy Toward Students' Achievement in Mathematical Multiple Representation Ability (MMRA). Jurnal Ilmiah Peuradeun, 6(1), 31-40.

Hendriana, H., Rohaeti, E. E., \& Hidayat, W. (2017). Metaphorical Thinking Learning and Junior High School Teachers' Mathematical Questioning Ability. Journal on Mathematics Education, $8(1), 55-64$.

Hidayat, W., \& Sariningsih, R. (2018). Kemampuan pemecahan masalah matematis dan adversity quotient siswa SMP melalui pembelajaran open ended. JNPM (Jurnal Nasional Pendidikan Matematika), 2(1), 109-118.

Huda, M. (2013). Model-model pengajaran dan pembelajaran. Yogyakarta: Pustaka Pelajar, 265.

Izzati, N., \& Suryadi, D. (2010). Komunikasi matematik dan pendidikan matematika realistik. Prosiding Seminar Nasional Matematika Dan Pendidikan Matematika, 27, 721-729.

Kurnia, R. D. M., Mulyani, I., Rohaeti, E. E., \& Fitrianna, A. Y. (2018). Hubungan Antara Kemandirian Belajar dan Self Efficacy Terhadap Kemampuan Komunikasi Matematis Siswa SMK. Jurnal Ilmiah Pendidikan Matematika, 3(1), 59-64.

Mullis, I. V. S., Martin, M. O., Minnich, C. A., Stanco, G. M., Arora, A., Centurino, V. A. S., \& Castle, C. E. (2012). TIMSS 2011 Encyclopedia: Education Policy and Curriculum in Mathematics and Science (1st ed.). ERIC.

Niasih, N., Romlah, S., \& Zhanty, L. S. (2019). Analisis Kemampuan Komunikasi Matematis Siswa SMP di Kota Cimahi Pada Materi Statistika. Jurnal Cendekia : Jurnal Pendidikan Matematika, 3(2), 266-277. https://doi.org/10.31004/cendekia.v3i2.107

OECD, P. (2016). Results (Volume I): Excellence and equity in education. Paris: OECD Publishing.

Sariningsih, R., \& Purwasih, R. (2017). Pembelajaran problem based learning untuk meningkatkan kemampuan pemecahan masalah matematis dan self efficacy mahasiswa calon guru. Jurnal Nasional Pendidikan Matematika., 1(1), 163-177.

Sugandi, A. I., \& Akbar, P. (2019). Efektivitas Penerapan Strategi React Terhadap Kemampuan Koneksi Matematis dan Self-Efficacy Siswa SMP. Jurnal Cendekia: Jurnal Pendidikan Matematika, 3(2), 431-436. https://doi.org/10.31004/cendekia.v3i2.117

Sugandi, A. I., \& Bernard, M. (2018). Penerapan Pendekatan Kontekstual Terhadap Kemampuan Pemahaman Dan Komunikasi Matematis Siswa Smp. Jurnal Analisa, 4(1), 172-178. https://doi.org/10.15575/ja.v4i1.2364

Syasri, S. I. R., Hasanuddin, H., \& Noviarni, N. (2018). Peningkatan Kemampuan Komunikasi Matematis: Pengembangan Lembar Kerja Siswa Berbasis Model Pembelajaran Kooperatif Tipe Think Talk Write untuk Siswa Sekolah Menengah Pertama. JURING (Journal for Research in Mathematics Learning), 1(1), 43-54.

Wijayanto, A. D., Fajriah, S. N., \& Anita, I. W. (2018). Analisis Kemampuan Komunikasi Matematis Siswa Smp Pada Materi Segitiga Dan Segiempat. Jurnal Cendekia: Jurnal Pendidikan Matematika, 2(1), 97-104. https://doi.org/10.31004/cendekia.v2i1.36

Witarsa, F. I. (2017). The effect of cooperative learning with student Facilitator and explaining (sfae) model on students' Willingness to speak up. International Journal Pedagogy of Social Studies, 2(1), 11-18. 